\title{
Assessment of Genetic Diversity in Labeo gonius (Hamilton, 1822) through Microsatellite Marker in Nanak Sagar and Dhaura Reservoirs of Uttarakhand, India
}

\author{
Mohd Danish* and I.J. Singh \\ Department of Fisheries Resource Management, College of Fisheries, \\ Pantnagar-263145, UK, India \\ *Corresponding author
}

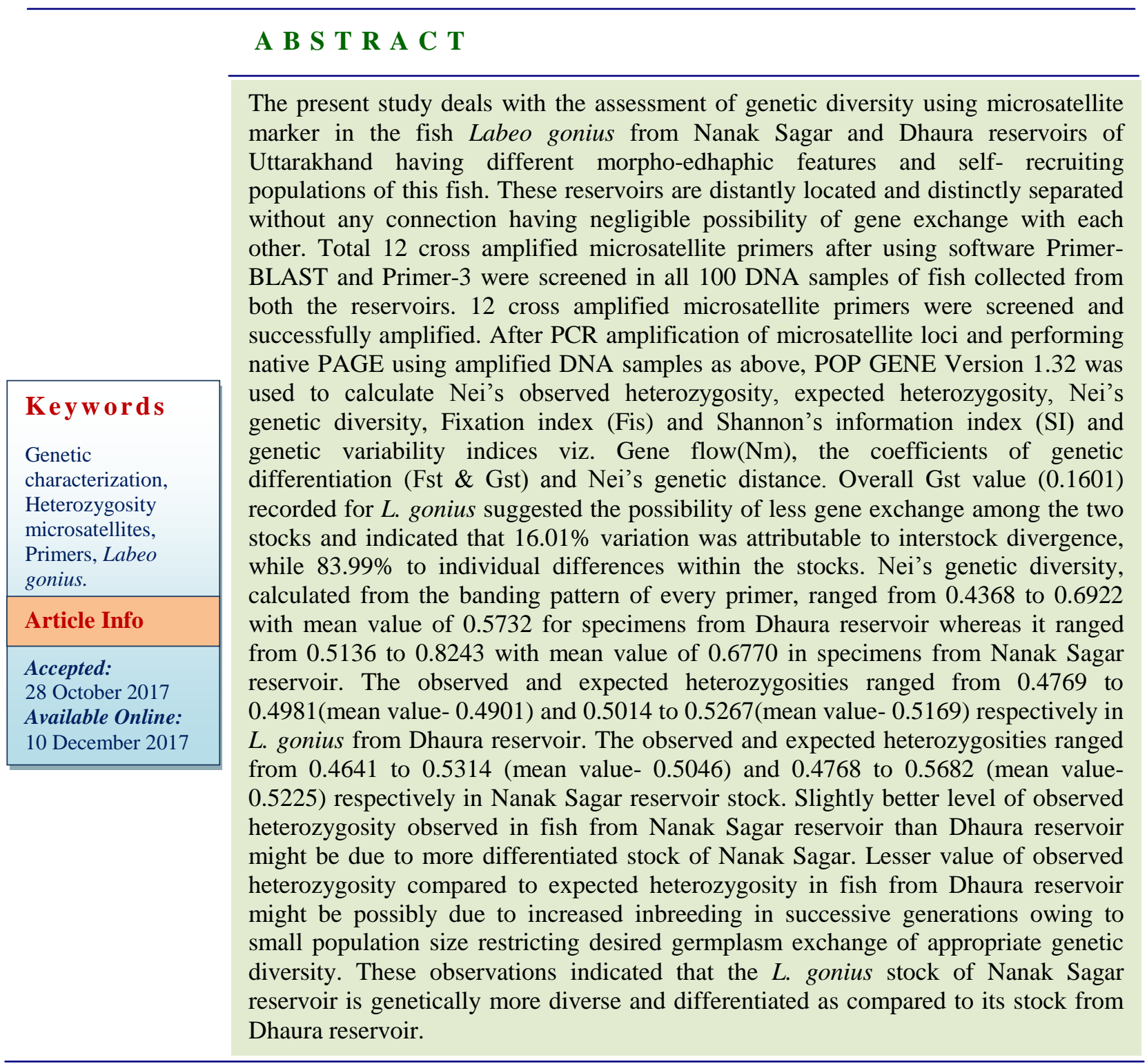




\section{Introduction}

Labeo gonius (Hamilton, 1822), a common Cyprinid species, is widely distributed in water bodies of North India, Asom, Odisha and along the east coast up to the Krishna river in India. It is a dominant fish species in different reservoirs of Uttarakhand and has a larger scope as potential candidate species for aquaculture. It spawns during the south- west monsoon during July to August. In Uttarakhand state a major part of aquatic resources is covered by reservoir $(18,931 \mathrm{ha})$ followed by rivers $(2700 \mathrm{~km})$ and ponds $(600$ ha). Two major reservoirs of Uttarakhand viz. Dhaura (1200 ha) and Nanak Sagar (4262 ha) are greatly subjected to environmental aberrations like reduction in water volume, increased sedimentation and water abstraction, catchment area degradation due to siltation, drying of water during summer season, conversion of water area into marshy land due to soil erosion caused by deforestation which makes status of different fishes highly vulnerable and subject to unpredictable genetic changes in these reservoirs. The fish fauna of these reservoirs mainly comprises of various species of catfishes, major carps and minor carps. $L$. gonius, a minor carp contributes substantially in catches of these reservoirs and enjoys a good market value as a food fish in the state. At present, its fishery is flourishing well in these reservoirs but for insuring good future prospects for $L$. gonius fishery early attention is required before its decline as practically no attention has been paid for stock assessment, sustainable utilization and genetic management of this species till now. Status of genetic structure of fish is considered essential for their controlled propagation, stock improvement and developing conservation plans. To conserve intra-specific genetic diversity of the fish the status of genetic diversity of the concerned species is a pre-requisite for developing management strategies. The data on genetic diversity can be effectively used to provide scientific basis for developing measures for conservation and management of natural population of the targeted species. Heterozygosity is an important measurement of genetic diversity level and has got much attention from ecologists and aqua-culturists ( $\mathrm{Xu}$ et al., 2001). The best estimate of genetic variation in natural population is the mean observed heterozygosity (Ho) per locus which varies non- randomly between loci, populations and species (Allendorf and Utter, 1979). Use of molecular markers, especially microsatellites, has been recognized to have great potential in revolutionizing the genetic management of fishery stocks for controlling the level of inbreeding and loss of genetic diversity through its ability to detect genetic uniqueness of individuals, populations or species (Lakra et al., 2007). Microsatellites or simple sequence repeats (SSRs) are short tandem repeat motifs (1-6 bases) with high level of allelic polymorphism and codominant inheritance (DeWoody and Avise, 2000). Microsatellites tend to be evenly distributed in the genome on all chromosomes and all regions of the chromosome (Chistiakov et al., 2006). Microsatellites have been found inside gene coding regions, introns and in the non-gene sequences (Liu et al., 2001). Microsatellites markers are preferable because they are co-dominant and highly polymorphic as compared to other genetic markers (Liu and Cordes, 2004) and have been proved to be very useful in revealing information about allele frequency, heterozygosity, population differentiation, inbreeding co-efficient, gene flow, linkage disequilibrium, stock identification and other parameters that are crucial measures of genetic diversity and population genetics. Recently, microsatellite markers have been developed for some Indian fishes such as Labeo rohita (Das et al., 2005; Patel et al., 2009) and Catla catla (McConnell et al., 
2001), Chitala chitala (Puniya et al.,2006) and Cirrhinus mrigala (Lal et al.,2011). Previously genetic diversity studies in $L$. gonius from three reservoirs of Uttarkhand has been done through allozyme and RAPD markers (Tewari et al., 2013a and b) but accuracy of predictions based on these markers has always been a matter of concern. Present study is the first attempt to assess the genetic variability status of $L$. gonius from two reservoirs- Dhaura and Nanak Sagar located in Tarai region of Uttarakhand through microsatellite marker with the aim of devising desirable management practices to conserve the available genetic resources of this fish for its sustainable production in these reservoirs.

\section{Materials and Methods}

Hundred live specimens (50 from each reservoir) of the fish, L. gonius were collected for present study from commercial catches of Nanak Sagar and Dhaura reservoirs. Kidney tissue were dissected out by using sterilized scissors and forceps and stored at $-86^{\circ} \mathrm{C}$ in deep freezer for further analysis. DNA was isolated from the dissected kidney tissue using DNA isolation kit purchased from Genei (Ltd.), Bangalore, India. Total twelve cross amplified microsatellite primers were used. To amplify the repeat regions, primers were analysed using the web based tool (http://primer3.sourceforge.net) Primer3 (Rozen and Skaletsky, 2000) with an optimum annealing temperature of $55^{\circ} \mathrm{C}$ and a minimum GC content of $40-70 \%$.

\section{Amplification of microsatellite loci and analysis of microsatellite data}

All the twenty microsatellite primers were initially screened in 2-2 DNA samples of $L$. gonius collected from Nanak Sagar and Dhaura reservoirs. A total of 12 cross amplified microsatellite loci were successfully amplified which produced clear and polymorphic bands. PCR amplification of microsatellite loci were performed in a $25 \mu \mathrm{l}$ reaction mixture, which included $1 \mathrm{X}$ PCR buffer $(10 \mathrm{mM}$ Tris- $\mathrm{HCl} \mathrm{pH} 9.0,50 \mathrm{mM}$ $\mathrm{KCl}), 0.2 \mathrm{mM}$ of each dNTP, $2.0 \mathrm{mM}$ of $\mathrm{MgCl}_{2}, 5 \mathrm{p}$ mol of each primer, $1.5 \mathrm{U}$ Taq DNA polymerase and 25-50 ng of template DNA using PCR (Eppendorf, USA). Initial denaturation was performed at $94^{\circ} \mathrm{C}$ for 3 minutes followed by 30 cycles of $94^{\circ} \mathrm{C}$ for 30 seconds, locus specific annealing temperatures $\left(52-64^{\circ} \mathrm{C}\right)$ for 60 seconds and $72^{\circ} \mathrm{C}$ for 90 seconds and a final elongation of 1 cycle at $72{ }^{\circ} \mathrm{C}$ for $8 \mathrm{~min}$ followed by storing it at $4^{\circ} \mathrm{C}$. Amplified products were mixed with $2 \mu 1$ of gel loading dye and then separated on $6 \%$ denaturing polyacrylamide gel with 1x TBE on PAGE Gel along with standard marker $\Phi$ X 174/ Hinf I marker at constant power supply of 25 volts for $2 \mathrm{hrs}$. Polymorphic information content (PIC) of individual primer was estimated using the formula: PIC $=1-1 / n \sum_{i=1}^{n} P i j$ Where Pij is the frequency of $\mathrm{jth}$ allele. After performing native PAGE, POP GENE Version 1.32 (Raymond and Rousset, 1998) was used to calculate Nei's observed heterozygosity (Ho), expected heterozygosity (He), Fixation index (Fis) and genetic variability indices viz. Gene flow (Nm), the coefficients of genetic differentiation (Fst \& Gst) and Nei's genetic distance. Nei's genetic diversity (Hi) was calculated from the banding pattern of every screened primer across all the loci. Individual genotypes were scored using the Gene Mapper (version 4.0; Applied Biosystems) with a size standard and an internal control for allele calling. Each allele was coded according to its size in nucleotide base pairs (bp). Possible null alleles and genotyping errors caused by stuttering and/or large-allele dropout were tested using MICROCHECKER (Van Oosterhout et al., 2004). Scoring and human error were estimated by 
duplicate analyses. The polymorphic information content (PIC) was calculated by using the CERVUS version 3.03 (Kalinowski et al., 2007).

\section{Results and Discussion}

Screening of microsatellite primers in $L$. gonius

Microsatellite primers selected for further study based on amplifying successfully and exhibiting desired level of polymorphism have been summarized in table 1. Twelve Primer-BLAST cross amplified microsatellite primers for L. gonius exhibited polymorphism.

Microsatellite primers amplification in $L$. gonius from Nanak Sagar reservoir

Microsatellite primers amplification values across all loci in L. gonius from Nanak Sagar reservoir are recorded in table 2 . Number of alleles per locus ranged from 5-9 with mean value of 7.08 per locus. A total of 8 SSR loci were scored by the primer PL-01. The product size ranged from $0.11 \mathrm{~Kb}$ to $0.30 \mathrm{~Kb}$ and the average expected genetic diversity and PIC value of the primer were 0.635 and 0.71 respectively.

A total number of 7 SSR loci were scored by the primer PL-02. The product size ranged from $0.14 \mathrm{~Kb}$ to $0.35 \mathrm{~Kb}$ and the average expected genetic diversity and PIC value of the primer were 0.783 and 0.68 respectively. The totals of 6 SSR loci were scored for the primer PL-03 with product size ranged from 0.25 to $0.37 \mathrm{~Kb}$ and the average expected genetic diversity and PIC value of the primer were 0.635 and 0.63 respectively. A total of 8 SSR polymorphic loci were scored for the primer PL-08. The product size ranged from $0.22 \mathrm{~Kb}$ to $0.48 \mathrm{~Kb}$ and the average expected genetic diversity and PIC value of the primer were 0.680 and 0.69 respectively. Total numbers of 6 SSR loci were scored by the primer PL-10. The product size ranged from $0.18 \mathrm{~Kb}$ to $0.70 \mathrm{~Kb}$ and the average expected genetic diversity and PIC value of the primer were 0.765 and 0.60 respectively. 7 SSR loci were scored by the primer PL-11 and the product size was $0.25 \mathrm{~Kb}$ to $0.65 \mathrm{~Kb}$ and the average expected genetic diversity and PIC value of the primer were 0.737 and 0.64 . A total of 8 SSR loci with product size ranged $0.20 \mathrm{~Kb}$ to $0.70 \mathrm{~Kb}$ were scored for the primer PL-13. The average expected genetic diversity and PIC value were 0.824 and 0.68 respectively.

Total 5 SSR loci were scored by the primer PL-14 and the average expected genetic diversity and PIC value of the primer were 0.796 and 0.63 respectively and product size ranged from 0.10 to $0.25 \mathrm{~kb}$. 6 SSR loci were scored by the primer PL-15 and the average expected genetic diversity and PIC value of the primer were 0.513 and 0.61 respectively and product size ranged from 0.13 to $0.40 \mathrm{~kb}$. 7 SSR loci were scored by the primer PL-16 and the average expected genetic diversity and PIC value of the primer were 0.576 and 0.65 respectively. Product size ranged from 0.17 to $0.40 \mathrm{~kb} .9$ SSR loci were scored by the primer PL-17 and the average expected genetic diversity and PIC value of the primer were 0.650 and 0.74 respectively and product size ranged from 0.15 to $0.30 \mathrm{~kb} .8 \mathrm{SSR}$ loci were scored by the primer PL-20 and the average expected genetic diversity and PIC value of the primer were 0.630 and 0.67 respectively and product size ranged from 0.20 to $0.40 \mathrm{~kb}$.

\section{Microsatellite primers amplification in $L$. gonius from Dhaura reservoir}

Microsatellite primers amplification values across all loci in L. gonius from Dhaura reservoir are recorded in table 2. Number of 
alleles per locus ranged from 5-9 with mean value of 6.91 per locus. A total of 7 SSR loci were scored by the primer PL-01. The product size ranged from $0.10 \mathrm{~Kb}$ to $0.25 \mathrm{~Kb}$ and the average expected genetic diversity and PIC value of the primer were 0.510 and 0.67 respectively. A total number of 6 SSR loci were scored by the primer PL-02. The product size ranged from $0.20 \mathrm{~Kb}$ to $0.40 \mathrm{~Kb}$ and the average expected genetic diversity and PIC value of the primer were 0.634 and 0.60 respectively.

The total of 7 SSR loci were scored for the primer PL-03 with product size ranged from 0.20 to $0.42 \mathrm{~Kb}$ and the average expected genetic diversity and PIC value of the primer were 0.540 and 0.65 respectively. The total of 9 SSR loci was scored for the primer PL-08. The product size ranged from $0.18 \mathrm{~Kb}$ to 0.53 $\mathrm{Kb}$ and the average expected genetic diversity and PIC value of the primer were 0.436 and 0.73 respectively. Total numbers of 6 SSR loci were scored by the primer PL-10 and the product size ranged from $0.38 \mathrm{~Kb}$ to $0.65 \mathrm{~Kb}$ and the average expected genetic diversity and PIC value of the primer were 0.595 and 0.61 respectively. 7 SSR loci was scored by the primer PL-11and the product size was $0.32 \mathrm{~Kb}$ to $0.68 \mathrm{~Kb}$ and the expected genetic diversity and PIC value of the primer were 0.652 and 0.64 respectively. 9 SSR loci with product size ranged $0.28 \mathrm{~Kb}$ to $0.74 \mathrm{~Kb}$ was scored for the primer PL-13.

The average expected genetic diversity and PIC value were 0.623 and 0.73 respectively. 6 SSR loci were scored by the primer PL-14 and the average expected genetic diversity and PIC value of the primer were 0.571 and 0.61 respectively and product size ranged from 0.10 to $0.20 \mathrm{~kb}$. 8 SSR loci were scored by the primer PL-15 and the average expected genetic diversity and PIC value of the primer were 0.692 and 0.66 respectively and product size ranged from 0.25 to $0.35 \mathrm{~kb}$. $5 \mathrm{SSR}$ loci were scored by the primer PL-16 and the average expected genetic diversity and PIC value of the primer were 0.497 and 0.58 respectively.

Product size ranged from 0.25 to $0.45 \mathrm{~kb}$. A total of 7 SSR loci were scored by the primer PL-17 and the average expected genetic diversity and PIC value of the primer were 0.548 and 0.63 respectively and product size ranged from 0.15 to $0.30 \mathrm{~kb}$. 6 SSR loci were scored by the primer PL-20 and the average expected genetic diversity and PIC value of the primer were 0.578 and 0.61 respectively and product size ranged from 0.20 to $0.45 \mathrm{~kb}$.

\section{Microsatellite variation based Genetic diversity in L. gonius from Nanak Sagar and Dhaura reservoirs}

Microsatellite variation based genetic diversity values in L. gonius from Dhaura and Nanak Sagar reservoirs are recorded in tables 3 and 4 respectively. Nei's genetic diversity values ranged from 0.4368 to 0.6922 with mean value of 0.5732 for specimens from Dhaura reservoir whereas it ranged from 0.5136 to 0.8243 with mean value of 0.6770 in specimens from Nanak Sagar reservoir.

The observed and expected heterozygosities ranged from 0.4769 to 0.4981 (mean value 0.4901 ) and 0.5014 to 0.5267 (mean value0.5169 ) respectively in L. gonius from Dhaura reservoir.

The observed and expected heterozygosities ranged from 0.4641 to 0.5314 (mean value0.5046 ) and 0.4768 to 0.5682 (mean value$0.5225)$ respectively in Nanak Sagar reservoir stock. The mean values of Fis were found to be 0.124 in Nanak Sagar reservoir and 0.145 in Dhaura reservoir. Mean values for Shannon's information index for all microsatellite loci in L. gonius were 1.1862 for Dhaura reservoir population and 1.2342 for Nanak Sagar population. 
Table.1 Primer-BLAST designed microsatellite primers for L. gonius

\begin{tabular}{|c|c|c|c|}
\hline Locus & Primer Sequence(5'-3') & Annealing Temp & Annealing Time \\
\hline PL-01 & $\begin{array}{l}\text { F-GAAAGCTGCTCGTCCTTGAA } \\
\text { R-GAAAGCTGCTCGTCCTTGAA }\end{array}$ & $52^{\circ} \mathrm{C}$ & $1 \mathrm{~min} 30 \mathrm{sec}$ \\
\hline PL-02 & $\begin{array}{l}\text { F-GGGTGTGGGAGAGAAAGAGAG } \\
\text { R-GGAGTCTGACAAATGCAGCAAG }\end{array}$ & $64^{\circ} \mathrm{C}$ & $1 \mathrm{~min}$ \\
\hline PL-03 & $\begin{array}{l}\text { F-TCTCAGTGGGTGTCATTACCTG } \\
\text { R-CCCATCAAACCATCTCTCTAGC }\end{array}$ & $52^{\circ} \mathrm{C}$ & $1 \mathrm{~min}$ \\
\hline PL-08 & $\begin{array}{l}\text { F-CTGACACTCTTATCTCGCTGCC } \\
\text { R-GACCTGAGCAAACAAACCTCAT }\end{array}$ & $53^{\circ} \mathrm{C}$ & $1 \mathrm{~min} 30 \mathrm{sec}$ \\
\hline PL-10 & $\begin{array}{l}\text { F-TCTCTCTTTGTCTTTCCCCTTG } \\
\text { R-CACAAGCCACTGTTTAGCTTCA }\end{array}$ & $64^{\circ} \mathrm{C}$ & $1 \mathrm{~min}$ \\
\hline PL-11 & $\begin{array}{l}\text { F-CAAATCTGTGAACATGCAAGC } \\
\text { R-CCTAGTCCCACTCTAGTCAGCA }\end{array}$ & $58^{\circ} \mathrm{C}$ & $1 \mathrm{~min} 30 \mathrm{sec}$ \\
\hline PL-13 & $\begin{array}{l}\text { F-AGATAAGACCCTTCTTCCTCGG } \\
\text { R-TTTATTAGGGAGCGTCGAGTG }\end{array}$ & $64^{\circ} \mathrm{C}$ & $1 \mathrm{~min}$ \\
\hline PL-14 & $\begin{array}{l}\text { F-CTGTTGGTGACTGTAGGGTGAA } \\
\text { R-GAGAACTCGGTTTGAACATGC }\end{array}$ & $58^{\circ} \mathrm{C}$ & $1 \mathrm{~min} 30 \mathrm{sec}$ \\
\hline PL-15 & $\begin{array}{l}\text { F-ACAGTAATCTTGTGTCTGTCTCTCTC } \\
\text { R-GTCTAAACGTGTCTGAGCTGTG }\end{array}$ & $57^{\circ} \mathrm{C}$ & $1 \mathrm{~min} 30 \mathrm{sec}$ \\
\hline PL-16 & $\begin{array}{l}\text { F-TGAATGTTTCCAGTCACCACAT } \\
\text { R-GTAATGCAGCGGAGAATAAACC }\end{array}$ & $57^{\circ} \mathrm{C}$ & $1 \mathrm{~min}$ \\
\hline PL-17 & $\begin{array}{l}\text { F-ACAATTCCTGTGTCAACTGTGC } \\
\text { R-TACCGTCTCAGTCTCTTTTCGG }\end{array}$ & $55^{\circ} \mathrm{C}$ & $1 \mathrm{~min}$ \\
\hline PL-20 & $\begin{array}{l}\text { F-ATAGTCGAAATTGGTCCTCTGC } \\
\text { R- CAATACCATGACTGAAGTGCC }\end{array}$ & $55^{\circ} \mathrm{C}$ & $1 \mathrm{~min} 30 \mathrm{sec}$ \\
\hline
\end{tabular}

Table.2 Microsatellite primers amplification in L. gonius from Nanak Sagar and Dhaura reservoir

\begin{tabular}{|c|c|c|c|c|c|c|}
\hline \multirow{2}{*}{ Locus } & \multicolumn{2}{|l|}{ Nanak Sagar reservoir } & \multicolumn{3}{l|}{ Dhaura reservoir } \\
\cline { 2 - 7 } & $\begin{array}{c}\text { Amplified } \\
\text { Product (Kb) }\end{array}$ & $\begin{array}{l}\text { Number } \\
\text { of alleles }\end{array}$ & (PIC) & $\begin{array}{l}\text { Amplified } \\
\text { Product (Kb) }\end{array}$ & $\begin{array}{l}\text { Number } \\
\text { of alleles }\end{array}$ & (PIC) \\
\hline PL-01 & $0.11-0.30$ & 8 & 0.71 & $0.10-0.25$ & 7 & 0.67 \\
\hline PL-02 & $0.14-0.35$ & 7 & 0.68 & $0.20-0.40$ & 6 & 0.60 \\
\hline PL-03 & $0.25-0.37$ & 6 & 0.63 & $0.20-0.42$ & 7 & 0.65 \\
\hline PL-08 & $0.22-0.48$ & 8 & 0.69 & $0.18-0.53$ & 9 & 0.73 \\
\hline PL-10 & $0.18-0.70$ & 6 & 0.60 & $0.38-0.65$ & 6 & 0.61 \\
\hline PL-11 & $0.25-0.65$ & 7 & 0.64 & $0.32-0.68$ & 7 & 0.64 \\
\hline PL-13 & $0.20-0.70$ & 8 & 0.68 & $0.28-0.74$ & 9 & 0.73 \\
\hline PL-14 & $0.10-0.25$ & 5 & 0.59 & $0.10-0.20$ & 6 & 0.61 \\
\hline PL-15 & $0.13-0.4$ & 6 & 0.61 & $0.25-0.35$ & 8 & 0.66 \\
\hline PL-16 & $0.17-0.40$ & 7 & 0.65 & $0.25-0.45$ & 5 & 0.58 \\
\hline PL-17 & $0.15-0.30$ & 9 & 0.74 & $0.15-0.30$ & 7 & 0.63 \\
\hline PL-20 & $0.2-0.40$ & 8 & 0.67 & $0.2-0.45$ & 6 & 0.61 \\
\hline
\end{tabular}


Table.3 Genetic Diversity of L. gonius from Dhaura Reservoir based on Microsatellite markers

\begin{tabular}{|c|c|c|c|c|c|}
\hline Locus & $\begin{array}{l}\text { Observed } \\
\text { Heterozygosity } \\
\text { (Ho) }\end{array}$ & $\begin{array}{l}\text { Expected } \\
\text { Heterozygosity } \\
\text { (He) }\end{array}$ & $\begin{array}{l}\text { Nei's genetic } \\
\text { Diversity } \\
\text { (Hi) }\end{array}$ & $\begin{array}{l}\text { Shannon's } \\
\text { Information } \\
\text { Index }\end{array}$ & $\begin{array}{l}\text { Fixation } \\
\text { Index } \\
\text { Fis (-ve) }\end{array}$ \\
\hline PL-01 & 0.4769 & 0.5014 & 0.510 & 1.2596 & 0.123 \\
\hline PL-02 & 0.4961 & 0.5042 & 0.634 & 1.0764 & 0.133 \\
\hline PL-03 & 0.4883 & 0.5286 & 0.540 & 1.1889 & 0.148 \\
\hline PL-08 & 0.4961 & 0.5143 & 0.436 & 1.1743 & 0.185 \\
\hline PL-10 & 0.4865 & 0.5221 & 0.595 & 1.2573 & 0.132 \\
\hline PL-11 & 0.4947 & 0.5129 & 0.652 & 1.2589 & 0.110 \\
\hline PL-13 & 0.4838 & 0.5224 & 0.623 & 1.1320 & 0.105 \\
\hline PL-14 & 0.4919 & 0.5231 & 0.571 & 1.1250 & 0.103 \\
\hline PL-15 & 0.4861 & 0.5127 & 0.692 & 1.1124 & 0.111 \\
\hline PL-16 & 0.4959 & 0.5228 & 0.497 & 1.4021 & 0.109 \\
\hline PL-17 & 0.4872 & 0.5125 & 0.548 & 1.2269 & 0.099 \\
\hline PL-20 & 0.4981 & 0.5267 & 0.578 & 1.0214 & 0.092 \\
\hline Mean & $\mathbf{0 . 4 9 0 1}$ & $\mathbf{0 . 5 1 6 9}$ & $\mathbf{0 . 5 7 3 2}$ & $\mathbf{1 . 1 8 6 2}$ & $\mathbf{0 . 1 4 5}$ \\
\hline
\end{tabular}

Table.4 Genetic Diversity of L. gonius from Nanak Sagar based on Microsatellite markers

\begin{tabular}{|c|c|c|c|c|c|}
\hline Locus & $\begin{array}{l}\text { Observed } \\
\text { Heterozygosity } \\
\text { (Ho) }\end{array}$ & $\begin{array}{l}\text { Expected } \\
\text { Heterozygosity } \\
\text { (He) }\end{array}$ & $\begin{array}{l}\text { Nei's genetic } \\
\text { Diversity } \\
\text { (Hi) }\end{array}$ & $\begin{array}{l}\text { Shannon's } \\
\text { Information } \\
\text { Index }\end{array}$ & $\begin{array}{l}\text { Fixation } \\
\text { Index } \\
\text { Fis (-ve) }\end{array}$ \\
\hline PL-01 & 0.5171 & 0.5289 & 0.635 & 1.3675 & 0.103 \\
\hline PL-02 & 0.5282 & 0.5475 & 0.783 & 1.3354 & 0.120 \\
\hline PL-03 & 0.4737 & 0.4958 & 0.635 & 1.2519 & 0.118 \\
\hline PL-08 & 0.5314 & 0.5682 & 0.680 & 1.4005 & 0.155 \\
\hline PL-10 & 0.5287 & 0.5494 & 0.765 & 1.4299 & 0.105 \\
\hline PL-11 & 0.4721 & 0.4986 & 0.737 & 1.0563 & 0.090 \\
\hline PL-13 & 0.5135 & 0.5327 & 0.824 & 1.3321 & 0.085 \\
\hline PL-14 & 0.4641 & 0.4768 & 0.796 & 1.1042 & 0.098 \\
\hline PL-15 & 0.4859 & 0.4981 & 0.513 & 1.0368 & 0.091 \\
\hline PL-16 & 0.5278 & 0.5379 & 0.576 & 1.1525 & 0.081 \\
\hline PL-17 & 0.5282 & 0.5380 & 0.650 & 1.1103 & 0.115 \\
\hline PL-20 & 0.4853 & 0.4988 & 0.630 & 1.2335 & 0.081 \\
\hline Mean & $\mathbf{0 . 5 0 4 6}$ & $\mathbf{0 . 5 2 2 5}$ & $\mathbf{0 . 6 7 7 0}$ & $\mathbf{1 . 2 3 4 2}$ & $\mathbf{0 . 1 2 4}$ \\
\hline
\end{tabular}

Table.5 Genetic variability indices in L. gonius stocks from Nanak Sagar and Dhaura reservoirs

\begin{tabular}{l|c|c}
\hline \multicolumn{1}{c|}{ Parameters } & \multicolumn{2}{|c}{ Values } \\
\hline Coefficient of genetic differentiation (Fst) & \multicolumn{2}{|c}{0.093} \\
Estimation of Gene flow (Nm) & 1.276 \\
Total genetic diversity in population (Ht) & \multicolumn{2}{|c}{0.5274} \\
Within sample genetic diversity (Hs) & \multicolumn{2}{|c}{0.4430} \\
Coefficient of genetic differentiation (Gst) & \multicolumn{2}{|c}{0.1601} \\
Nei's genetic distance & \multicolumn{2}{|c}{0.2134} \\
P-Value & \multicolumn{2}{|c}{$0.0184 *$} \\
\cline { 2 - 3 } Observed number of alleles (na) & 4.9805 & 4.8126 \\
Effective number of alleles (ne) & 4.7762 & 4.5531 \\
\hline *Significant at $P<0.05$ & &
\end{tabular}


Genetic divergence in L. gonius stocks from Nanak Sagar and Dhaura reservoirs

Observations related with genetic divergence in L. gonius stocks from both reservoirs are presented in table 5. Genetic differentiation (P-value) for L. gonius across all loci among different population pairs in Nanak Sagar and Dhaura reservoirs was found to be 0.0184 . Values of Gene flow (Nm) and Nei's genetic distance among reservoir populations of $L$. gonius were found to be 1.276 and 0.1768 respectively. Values of coefficients of genetic differentiation (Fst \& Gst) observed were 0.093 and 0.1632 respectively for overall population of $L$. gonius. Total genetic diversity in overall population $(\mathrm{Ht})$ and within sample genetic diversity (Hs) was 0.5274 and 0.4430 , respectively. The observed (na) and effective number of alleles (ne) in $L$. gonius from Nanak Sagar reservoir were found to be 4.9805 and 4.7762 respectively and for Dhaura reservoir these values were 4.8126 and 4.5531 respectively.

The genetic diversity value (0.6770) based on observed and expected heterozygosities (0.5046 and 0.5225) in L. gonius from Nanak Sagar reservoir compared to genetic diversity value (0.5732) and observed and expected heterozygosities (0.4901 and 0.5169) from Dhaura reservoir indicated that its stock in Nanak Sagar reservoir exhibited better genetic diversity. These reservoirs are distantly located and distinctly separated without any connection hence having negligible possibility of gene exchange with each other and this also might be responsible for varied sub- structuring of the stocks of $L$. gonius. The values of Nei's genetic diversity in Nanak Sagar reservoir (0.6770) and in Dhaura reservoir (0.5732) in $L$. gonius through microsatellite marker are found to be higher than Nei's genetic diversity values in these reservoirs $(0.3980$ and 0.2243$)$ in L. gonius through RAPD marker (Tewari et al., 2013
b).Genetic diversity values based on codominant microsatellite markers are more accurate and preferable as compared to allozyme and dominant RAPD markers as these markers are highly polymorphic, capable of detecting small genetic differences (even single nucleotide base change variation) which is essential in studies on the genetic variability of the populations (Balloux and Lugonae, 2002). Nei's genetic diversity range (0.436 to 0.824 ) in L. gonius (over all loci) was found to be in similar range (0.679 to 0.874 ) reported in $T$. tambroides through microsatellite marker by Nguyen et al., (2007).Similar level of observed and expected heterozygosity values in Nanak Sagar population of $L$. gonius and lesser observed heterozygosity value compared to expected heterozygosity in fish from Dhaura might be possibly to some extent correlated with the level of inbreeding incidences in successive generations due to less effective population size limiting germplasm exchange required for maintaining appropriate genetic diversity. Large area of Dhaura gets dried up in summer and most fishes including L. gonius are extensively exploited even from deeper isolated pockets thus adversely affecting their effective population size $(\mathrm{Ne})$ available for breeding in the following breeding season. The mean values of observed heterozygosity in $L$. gonius from both the reservoirs were found to be comparable with the mean value of observed heterozygosity (0.46) reported for some other freshwater fishes (DeWoody and Avise, 2000). The observed heterozygosity range (over all loci) in L. gonius are found to be comparable with the observed heterozygosity range $(0.0000$ to 0.9000$)$ reported in Tor putitora using seven microsatellites loci developed from Catla catla and Barbus barbus by Mohindra et al., (2004). Same observations (heterozygosity range- $0.10-1.00$ and 0.500 to 0.870 ) were reported for other cyprinid fishes like silver carp and bighead carp by Tong et al., (2002); 
and in three wild and one farm population of L. rohita by Sahoo et al., (2014), respectively. However, the observed heterozygosity range in L. gonius was found to be higher than in Cirrhinus mrigala (0.247 to 0.333) reported from different rivers by Lal et al., (2004). The mean values of observed and expected heterozygosity in L. gonius from Nanak Sagar population using microsatellite marker was found to be comparable with the mean values (0.501 and 0.539 ) of observed and expected heterozygosity using allozymes marker in $L$. gonius from Nanak Sagar population (Tewari et al., 2013a).Small differences between observed values of population genetic diversity $(\mathrm{Hs}=0.4430)$ and total genetic diversity $(\mathrm{Ht}=0.5274)$ indicated moderate genetic differentiation among $L$. gonius stocks. Nei's genetic diversity results in $L$. gonius in present findings are well correlated with the observations made by Singh et al.,(2015) where five microsatellite loci was used to study the genetic diversity and characterization of different strains of common carp $C$. carpio L. and reported mean observed heterozygosity ranged $(0.45$ and 0.62) while expected heterozygosity ranged(0.32-0.68).

On the basis of calculated (na=4.9805 and 4.8126) observed number of alleles and effective (ne=4.7762 and 4.5531) number of alleles in Nanak Sagar and Dhaura reservoirs it is indicated that significant genetic variation is there within stocks of $L$. gonius in both reservoirs. However, relatively lower genetic variability in Dhaura stock as compared to Nanak Sagar stocks might be correlated with effective population size owing to fishing pattern in them. The problems of bottleneck, genetic drift and inbreeding depression, are correlated with small populations, effective population size to population genetic structure of fishes (Ayappan, 2011). Overall Gst value (0.1601) calculated for L. gonius suggested the possibility of less gene exchange among the two stocks and indicated that $16.01 \%$ variation was attributable to interstock divergence, while $83.99 \%$ to individual differences within the stocks. The moderate level genetic differentiation on the basis of calculated value of coefficient of genetic differentiation across all loci $(F s t=0.093)$ was present due to different population size as Dhaura reservoir have smaller population size than Nanak Sagar reservoir and this pattern of variation is relatively higher corresponds to that obtained (low level of differentiation) in other Indian fresh water fishes through microsatellites reported by Chaturvedi et al., (2011) in L. dero ( $\mathrm{Fst}=0.019)$ and by Gopalakrishnan et al., (2009) in L. dussumieri (Fst=0.041) whereas Appleyard and Mather, (2002) reported high $F_{S T}$ values (0.501 to 0.598) in two species of Oreochromis indicating there was little evidence of introgression between these species and Singh et al., (2012) reported low Fst value(0.035) in L. calbasu. Effective number of migrants per generation, an indicator of gene flow (Nm), calculated (1.276) among L.gonius populations is an indicative of negligible migration resulting in low gene flow level which indicated that very little gene exchange among the populations because of less number of migrants as these reservoirs are distinctly located from each other. Moreover, they are not interconnected at any point reject the chance of migration and gene exchange. Nei's genetic distance calculated between pairs of stocks of L. gonius from two reservoirs reveal larger genetic distance value (0.1768) between Nanak Sagar and Dhaura reservoir stocks. Value of genetic distance among $L$. gonius population is correlated with the value of genetic distance $(D=0.171$ to 0.199) reported by Khoo et al., (2002) in guppy fish, population $(\mathrm{D}=0.085-0.249)$. Comparison among the separate population pairs from these two reservoirs, distantly located from each other and having no connection with each other, $\mathrm{P}-$ value $(0.0184)$ 
show significant genetic differentiation at $\mathrm{P}<0.05$ among Nanak Sagar and Dhaura reservoirs populations. As genetic distance value increases with the increase in geographic distance, the observations on genetic distance in stocks of L. gonius from both the reservoirs might be correlated with the geographical distances $(70 \mathrm{~km})$ between the stocks of two distantly separated reservoirs.

On the basis of observations on heterozygosity (Ho and He), Nei's genetic diversity (Hi), Fixation Index (Fis), Shannon's Information Index (SI) and Genetic variability indices it can be inferred that L. gonius stock of Nanak Sagar reservoir is genetically more diverse and moderately differentiated compared Dhaura reservoir stock.

\section{References}

Allendorf, F. W. and Waples, R. S. (1996). Conservation and genetics of salmonid fishes. Conservation Genetics. Case Stories from Nature, 238-280.

Allendorf, F.W., and Utter, F.M. (1979). Population genetics. In W.S. Hoar and D.J.Randall (Eds.). Fish Physiology, 8. Academic Press, New York.pp.407-454.

Appleyard, S.A. and Mather, P.B. (2002). Genetic characterization of cultured Tilapia in Fiji using allozymes and RAPD. Asian Fisheries Science, 15, 249264.

Ayappan, S. (2011). Handbook of Fisheries and Aquaculture. pp.49-51.

Balloux, F., and Lugonae, M. N. (2002). The estimation of population differentiation with microsatellite markers. Molecular Ecology. 11,155-165.

Chaturvedi, A., et al., (2011). Population genetic structure and phylogeography of cyprinid fish, Labeo dero (Hamilton, 1822 ) inferred from allozyme and microsatellite DNA marker analysis. Molecular Biology, 38, 3513-3529.
Chistiakov, D.A., Hellemans, B., \& Volckaert, F.A.M. (2006). Microsatellites and their genomic distribution, evolution, function and applications: A review with special reference to fish genetics. Aquaculture, 255, 1-29.

Das, P., et al., (2005). Isolation and characterisation of polymorphic microsatellites in Labeo rohita and their cross species amplification in related species. Molecular Ecology Notes, 5, 231233.5 .

DeWoody, J.A., and Avise, J.C. (2000). Microsatellite variation in marine, freshwater and anadromous fishes compared with other animals. Journal of Fish Biology, 56(3), 461-473.

Gopalakrishnan, A., et al., (2009). Low genetic differentiation in the populations of the malabar carp Labeo dussumieri as revealed by allozymes, microsatellites and RAPD. Asian Fisheries Science, 22, 359-391.

Kalinowski, ST., Taper, M.L., and Marshall, T.C. (2007). Revising how the computer program CERVUS accommodates genotyping error increases success in paternity assignment. Molecular Ecology 16, 1099-1106.

Khoo, G., et al., (2002). Genetic diversity within and among feral populations and domesticated strains of the guppy in Singapore. Marine Biotechnology, 4, 367-378.

Lakra, W. S., et al., (2007). Fish genetics and conservation research in India: status and perspectives. Fish Physiology and Biochemistry, 33, 475-487.

Lal, K. K., et al., (2004). Identification of microsatellite DNA markers for population structure analysis in Indian major carp, Cirrhinus mrigala. Journal of Applied Ichthyology, 20, 87-91.

Lal, K.K., et al., (2011). Genetic variation in Hilsa shad (Tenualosa ilisha) population in River Ganges. Indian Journal of Fisheries, 51, 33-42

Liu, Z.J., and Cordes, J.F. (2004). DNA marker technologies and their applications in 
aquaculture genetics. Aquaculture, 238, $1-37$

Liu, Z.J., et al., (2001). Microsatellite containing genes from the channel catfish brain: Evidence of trinucleotide repeat expansion in coding region of nucleotide excision gene RAD23B. Biochemistry and Biophysics Research Communication, 289, 317-324.

McConnell, S. K., et al., (2001). Microsatellite markers from the Indian major carp species, Catla catla. Molecular Ecology Notes, 1, 115-116.

Mohindra, V., et al., (2004) Microsatellite loci to assess genetic variation in Tor putitora. Journal of Applied Ichthyology, 20,466469.

Nguven, T., et al.,(2007). Charecterization of microsatellite DNA markers for a mahseer species, Tor tambroides (Cyprinidae) and cross amplification in four congeners. Molecular Ecology Notes, 7, 11-17.

Patel, A., et al., (2009). Development of 21 new microsatellite markers in Labeo rohita (rohu). Animal Genetics, 40, 253-254.

Punia, P., et al., (2006). Polymorphic microsatellite markers isolated from partially enriched genomic library of Chitala chitala. Molecular Ecology Notes, 6, 1263-1265.

Raymond, M., and Rouseet, F. (1995). An exact test for population differentiation. Genetics and Evolution, 49, 1280-1283.

Rozen, S., and Skaletsky, H.J. (2000). Primer3 on the WWW for general users and for biologist programmers. Methods in Molecular Biology, 132, 365-386.

Sahoo, L., et al., (2014). Limited genetic differentiation in Labeo rohita (Hamilton 1822) populations as revealed by microsatellite markers. Biochemical Systematics and Ecology, 57, 427-431.

Singh, Ekta., et al., (2015). Microsatellite Based Genetic Diversity and Differentiation of Common Carp, Cyprinus carpio in Rajasthan (India).National Academy Science Letters, 38(3), 193-196.

Singh, Rajeev., et al.,(2012). Genetic diversity of Indian Major Carp, Labeo calbasu (Hamilton, 1822) populations inferred from microsatellite loci. Biochemical Systematics and Ecology, 44, 307-316.

Tewari Grishma., Singh, I. J., \& Barat, A.K. (2013b). Population structure analysis of L. gonius from three reservoirs of Uttarakhand using RAPD marker. Current Science, 105(2), 237-241.

Tewari, Grishma, et al., (2013a).Genetic diversity analysis using allozyme marker in Labeo gonius (Hamilton, 1822) from two reservoirs of Uttarakhand. African Journal of Biotechnology, 12(19), 25322539.

Tong, J., et al., (2002). Cross-species amplification in silver carp and bighead carp with microsatellite primers of common carp. Molecular Ecology Notes, 2, 245-247.

Van Oosterhout, C., et al., (2004). Micro Checker: software for identifying and correcting genotyping errors in microsatellite data. Molecular Ecology Notes, 4, 535-538.

$\mathrm{Xu}, \mathrm{Z}$. h., et al., (2001). Genetic diversity of wild and cultured Penaeus monodon in the philipines using microsatellites. Aquaculture, 199, 13-40.

\section{How to cite this article:}

Mohd Danish and Singh, I.J. 2017. Assessment of Genetic Diversity in Labeo gonius (Hamilton, 1822) through Microsatellite Marker in Nanak Sagar and Dhaura Reservoirs of Uttarakhand. Int.J.Curr.Microbiol.App.Sci. 6(12): 3937-3947. doi: https://doi.org/10.20546/ijcmas.2017.612.454 